\title{
RESEARCH and EVALUATION
}

\section{The state of HIV sector local governance in Malawi and Zambia: Evidence from five districts}

Commonwealth Journal of Local Governance

Issue 15: June 2014

http://epress.lib.uts.edu.au/ojs/index.php/cjlg

\author{
Justin Steyn \\ African Democracy Institute \\ Johannesburg \\ South Africa
}

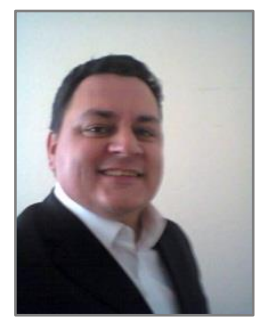

\begin{abstract}
This paper encapsulates the outputs of a Swiss Agency for Development Cooperation (SDC) funded project that aimed to improve the levels of HIV governance at the district level in Malawi and Zambia by encouraging public participation in an effort to more effective use of local resources. The methodology for this project, developed by the Institute for Democracy in Africa (Idasa) and SDC, included a barometer which assessed perceptions of district HIV governance among key stakeholders. Perceptions were gathered on governance principles of effectiveness, efficiency, rule of law, accountability, participation and equity. The stakeholders ranged from administrators, political representatives, community-based organisations and the private sector on the supply side and citizens on the demand or beneficiary side. The findings of the research indicate specific sector governance issues that may be generalised to governance. Communication and transparency appear to be major issues underpinning the bottlenecks and shortcomings in the HIV sector governance at the district level. Information gaps have given rise to accountability deficits and coordination deficiencies. Addressing these matters would make more effective use of resources and lessen dependence on external funding sources.
\end{abstract}

\section{Introduction}

This paper looks at the state of local HIV governance based on research and field data gathered in the implementation of development projects in Malawi and Zambia. In Malawi, the districts are Mangochi, Mzuzu and Mchinji. The two districts in Zambia are Kabwe and Choma. These districts provide the local context in which perception-based evidence of the conduct of service delivery and institutional performance was gathered. From these perceptions, recommendations to deal with the identified issues are made. It is concluded that promoting community ownership of the HIV response through improved democratic governance is perhaps the strongest contribution district stakeholders can make to fight the HIV epidemic over the long term. Building consensus around what needs to be done can hone the local HIV response as well as provide a catalyst for improving communication and the quality of information circulating between governors and the governed. 
The main rationale for this paper is to contribute to the improvement of human development by examining the issues involved in governance. Human development is very much contingent on improving the national administrative capacity to govern. Nowhere is this more evident in the area of HIV and AIDS governance, particularly in sub-Saharan Africa where over $60 \%$ of the world's HIV and AIDS cases are reported, and where resources are most stretched. In the upcoming reformulated Millennium Developmental Goals (MDG), governance is reputed to be given pride of place in MDG objectives after a general realisation that responsive service delivery and sustainable human development initiatives require resources to be stewarded in ways that build popular consensus.

\section{Defining governance and its purpose}

As a working definition, governance in this context is simply the decision-making process through which prudent and effective stewardship of financial and material resources is affected. This definition was part of the training curriculum developed for the participants in the fieldwork and derives from participatory democracy and development literature (see, for example, the World Bank's Poverty Reduction Strategy Paper Handbook and World Bank Country Policy and Institutional Assessment indicators). Any public resource has to be managed by means of accountable, participatory and rule-bound processes that enhance the planned effectiveness of resources expended in the pursuit of developmental objectives. International development partners have realised the need to fulfil the condition of improved governance and have begun to mainstream governance criteria into the sectors in which they have lent support. The Swiss Agency for Development and Cooperation (SDC) funded the research that made this paper possible. The primary concern of the SDC is food security and HIV. After funding general governance projects, the agency has elected to mainstream governance into their sectors of interest. As a result, improvements to governance are specifically related to the delivery of services in these two areas. The primary motivation is that if the targets set in the Millennium Development Goals are to be attained, improving the stewardship of resources is not only imperative, but also demands additional resources.

These resources cannot come from lending institutions or from development partners due to the conditions prevailing in the global economy. Instead additional resources ought to be found at the level at which they are to be expended. Community-led resource mobilisation is one such way to improve the effectiveness of service delivery in the HIV sector. It will promote community participation and ownership of the HIV response, enhancing positive perceptions of governance quality (Bratton and Sibanyoni 2006). Promoting community ownership of the HIV response through improved democratic governance is perhaps the strongest contribution districts can make to fighting the epidemic. 
HIV has been identified as a long-wave event, with effects and impacts likely to be felt long after infection rates subside (Whiteside and Sunter 2001). As HIV is a social event requiring prolonged vigilance and sustained, dedicated resource allocations, improvements to the linkages between stakeholders engaged in HIV governance and service provision are crucial to 'getting to zero' (UNAIDS 2010). In this the quality of existing services ought to be improved upon by means of assisting district actors to assess the perceptions of their performance within the administrative and participatory social dimensions of HIV governance.

\section{Profile of the AIDS epidemic in Malawi and Zambia}

Approximately 800,000 to 1 million Malawians are living with HIV. This translates into $12 \%$ of the total population (National AIDS Commission of Malawi 2009). By gender, women are roughly 1.3 times more likely to be infected than men, and by geographical location, one is three times more likely to be infected in the southern region than in central region and approximately 1.5 times more likely to be infected in southern region than in the northern region. Increasing levels of education and wealth are also predictors of higher prevalence rates. Zambia has an HIV prevalence of $14 \%$ of the adult population (15-49 age cohort). Much of the epidemic is driven by heterosexual sex. The most at risk population is the youth who contracting HIV in their first sexual contact. As a consequence, even faithfulness is not an effective protective measure.

As with Malawi, Zambia's HIV epidemic is driven by socio-economic dependencies, such as work migration and transactional survival sex, but much of these features are geographically localized due to the relative unequal distribution of wealth between provinces. The richer provinces tend to have higher prevalence than poorer provinces. In this instance, rural areas have a prevalence ranging from 5-15\% while urban areas range from 20-30\% prevalence (National AIDS Council of Zambia 2010). Again, as with Malawi, relative wealth in Zambia appears to be a group predictor of higher HIV prevalence due to the increased opportunities better off people have for sexual networking in relation to other income groups.

\section{AIDS governance in Malawi and Zambia}

AIDS governance structures are prescribed by international agreement and consensus. According to the UNAIDS model structure adopted by countries across the world, national machinery comprises one national plan, one monitoring and evaluation framework and one coordinating body. Due to the high impact of the epidemic, many countries have opted for strong political leadership models for the response. This is particularly valuable due to the high levels of stigma that accompanied HIV infection in the early days of the epidemic which saw openly HIV positive people excluded from holding public office and participating in the activities of the communities in which they lived. In some instances, HIV infected people continue to be denied access to medical services due to the high levels of self and social stigmatisation. 
In both Malawi and Zambia, the actors involved in the multi-sectoral response are almost identical. The primary actors are government ministries and departments, development partners, the private sector (including agricultural unions), politicians, traditional authorities, community based organisations, faith-based organisations, non-governmental organisations and AIDS networks and service organisations.

In these countries, political leadership is provided at the highest level from the office of the president. The national AIDS commissions or councils have an official representing the national AIDS response in the president's office. The National AIDS Commission coordinates all the activities occurring within the HIV sector. The national response is decentralised to the provincial level and then further onto the local district level, in the case of Zambia, and from national to local level in the case of Malawi.

In both instances, the national AIDS response is multi-sectoral and involves every government ministry and a number of international and local partners. In Malawi, HIV and nutrition are located within a shared ministerial portfolio. In Zambia, sector advisory groups (SAG) are part of each line ministry and each line ministry acts on SAG recommendations and reports to the National AIDS Council. The NAC in turn reports to the cabinet and the office of the president. In both countries, the Ministry of Health assumes responsibility for biomedical responses and for policy, planning, coordination and prevalence data collection through the behavioural and sentinel surveys.

In principle and policy, Zambia is mandated to exhibit a high degree of governance decentralisation but local government structures have little direct relationship to the HIV response, neither through planning and coordination nor the implementation of HIV activities. Such powers are centralised at the national and provincial level. In Malawi, decentralisation of services is relationally well developed with HIV planning, coordination and implementation falling under the authority of the local council. The absence of locally elected officials renders public participation less informed and effective than it might be in circumstances where such elected officials were present. In principle, local government structures are coordinating bodies for implementation of HIV and AIDS activities within their jurisdictions in both Malawi and Zambia. Due to the nature of demographic size and resource coordination requirements, local government further decentralises the response to urban community and rural village level. Local non-governmental organisations implementing activities in the area of HIV and AIDS are supported through these community AIDS governance structures. 


\section{Methodology: How the data was collected}

The project findings described here emerge from a sector governance assessment tool developed by the Institute for Democracy in Africa (Idasa) and the Swiss Agency for Development and Cooperation (SDC) for implementation in Malawi and Zambia. This project, designed to strengthen the system of sector governance in the area of HIV, included stakeholders from civil society, the private sector, politicians, government and citizens. The sector barometer is a self-assessment tool developed from policy documents and legal instruments that gathers sufficient evidence to assist implementing agents and service providers, both from government and civil society, to assess their performance and provide a discussion platform.

The principles comprising the framework of the governance assessment include effectiveness and efficiency, transparency and rule of law, political, administrative and social accountability, participation and equity. The perception data was gathered from stakeholders; politicians, the private sector, government employees and civil society. The civil society group included traditional leaders, faith-based organisations, community-based structures and local chapters of AIDS service organisations and networks. Citizens, as beneficiaries of policy and service outputs, are also stakeholders. The implementation cycle stratifies stakeholders into 5 groups of between 10-20 members. Every representative group had the opportunity to discuss issues of HIV governance within their own group. After stakeholders have discussed the issues amongst themselves and have completed the assessments which form the basis of the barometer, a quarter of the group were elected as their representatives. These representatives came together in a plenary session where the issues that were raised the respective groups were discussed to validate the points discussed and to share the scores of their assessments.

This methodology depersonalises the issues and creates an atmosphere in which points can be openly discussed within the group. For example, if there is a perception that government officials are corrupt, no blame is attributed to government officials. The question is reframed as, "what is it about governance that allows corruption to flourish?' Using perception data facilitates discussion and creates a platform for stakeholders to see the benefit of collaboration and joint goal-directed public work. This generates a higher degree of citizen ownership of governance processes, enhancing the democratisation of governance essential for sustainable community-centric development.

The findings are based on from discussion group material and from the data generated from governance assessments. Areas of exceptional performance are highlighted and the common issues of systemic malfunction are also emphasised because these areas are generic malfunctions in AIDS governance shared by all the surveyed districts in Malawi and Zambia. In Zambia, 185 participants took part in the implementation of the barometer while 286 participants took part in Malawi, giving a total of 471 participants. 


\section{Findings}

\section{The state of local AIDS governance}

While it must be made clear that there is no perfect system or ideal type of governance, good governance is largely accepted to be congruent with the definition set out in the introduction and with the principles set out in the methodology. This section states the fieldwork findings by each governance category; effectiveness and efficiency, transparency and rule of law, political, administrative and social accountability, participation and equity.

Under effectiveness and efficiency, the objective was to determine if there was a common plan or policy and perceptions of the level of compliance with the national policy, the relevance of, the policy to local conditions and the coherent communication of the issues involved in the stewardship of resources. The scoring of the participants in all districts aligned with their workshop discussions in the following areas: the national AIDS strategic plans are not widely made available. Roughly less than $5 \%$ of all participants had seen copies of the National AIDS Framework and even fewer had occasion to read it.

Irregular funding of HIV programs run from the district municipal offices and by local implementing partners is also a common issue. This affects the timely and effective implementation of activities. In all districts, to some degree, it was noted that the district AIDS coordinator's office was unaware of all the resources available for HIV activities. One of the participants in Mchinji said that donor funding is not communicated in the district and "[i]f all the money that donors put into Mchinji was accounted for, it [Mchinji] would be developed by now."

Additionally, communication between the stakeholders appears to be a major issue. In Choma in Zambia and Mchinji district in Malawi, it was specifically noted that little information reaches the communities on whether the district had reached its objectives. Political representatives were even more critical of this information process stating that, "[ $\mathrm{t}$ ]hey [the district executive committee] do things on their own [without informing representatives]." Government employees in all districts from both countries stated that their superiors seldom informed or briefed them on meetings and simply issued directives and delegated tasks without indicating the broader context of the activities, verbally or in writing.

Under the principle of transparency and rule of law, the openness of the stakeholders to outside scrutiny and the adherence to policy directives, as well as law, was interrogated. Three issues appeared to be generic in this regard. Tender information on HIV activities was not generally known, HIV components of budgets were not declared nor publicised and minutes of HIV meetings were not circulated. In Malawi, the absence of councillors brought the information deficit issue to the fore. Political representatives stated that, "the minute the councillors were not involved, we had a communication gap." This contrasts with the Zambian case in which elected councillors claimed that they were not included into the HIV response at all, on any organised level, in any district forum. 
In Kabwe district, civil society organisations (CSOs) stated that the government has the authority to order audits of CSO accounts. However, it is not clear if this is done since it is widely acknowledged among all stakeholders in both Kabwe and Choma that the district AIDS coordinator's office does not use its powers to force CSOs to declare their income from donor sources. This issue was prevalent in the perceptions of the stakeholders in Malawi as well. Stakeholders had to be made aware that the District AIDS Coordinator's office is a decentralised office of the National AIDS Council which is established and backed by an Act of parliament. This statutory power enables the district to force CSOs to sign memoranda of understanding (MoUs) with the district council. Such MoUs can be legally structured to compel implementing partners to declare income from development partners and donors. Since income of all the implementing partners is not known by the district executive council (Malawi) or the district development coordinating committee (Zambia), the coordination of HIV activities in the districts suffers as a result.

Under the principle of accountability, as touched on above, administrative, political and social accountability were examined. This tripartite principle examined the degree of internal administrative accountability and external accountability to politicians and citizens. From findings, it is apparent that accountability deficits are a direct outcome of poor political representation either by institutional design, the deliberate intent of some stakeholders, and the silence of politicians on HIV. The lack of administrative accountability is again a lack of political oversight, a lack of citizen engagement and unclear funding arrangements. It is not stipulated in constituency development funds (CDFs) how much goes for HIV activities in Zambia. In Malawi, there is no legal compulsion to use funds allocated to HIV for HIV activities in the district. As a result, funds can be budgeted for HIV activities in the planning phases of the district plans but diverted into other priority areas in the implementation phase.

What appeared to be the case was that an information asymmetry allowed stakeholders, whom the administrators viewed as troublesome or as unable to directly contribute to activity implementation, to be excluded from district stakeholder fora. The public disclosure of roles and responsibilities in fieldwork platforms was highly beneficial in environs in which information was viewed as power, being either withheld or selectively disseminated, depending on the positions of the people in the district power hierarchy.

Accountability, particularly administrative accountability, is further impacted on by a lack of widespread public knowledge of codes of conduct, uses and purposes of the constituency and community development funds, audit reports and the roles and responsibilities of the different stakeholders in the multisectoral response. While some districts claimed that financial information was made available, such as Mzuzu and Mangochi, widespread knowledge of budget access points was low among almost all of the stakeholders. In Mchinji, the political representatives stated that 
"[w] are not informed of budget deviations" and "stakeholders are not consulted [by council administrators on budget planning]." They further stated that this is an undesirable state of affairs because "[w] can be cheated later on [and told] that there is no money [for HIV activities]."

National legislation in both countries stipulates that councillors and political representatives are among the stakeholders to be consulted and to provide oversight of the implementation of local HIV activities, which, in the specific case of Mchinji, was clearly not happening. Therefore, political accountability is a key part of the national and local response. In both Malawi and Zambia, districts had made unintentional and deliberate efforts to exclude politicians either through a lack of knowledge of the primary planning documents, such as the National AIDS Strategic planning documents, or due to a fear of political interference in district activities. In two districts, namely Mchinji and Choma, politicians were included into the district's HIV governance structures as soon as the roles and responsibilities of the elected representatives were made public. Information access appears to be a major issue, particularly because community representatives, such as councillors, are not considered part of the multisectoral response. In Mzuzu, it was stated that politicians were not included into the district's HIV governance structure due to a fear that they would politicise administrative issues. This view was challenged in plenary groups as anyone can politicise an issue. The exclusion of public representatives from district stakeholder groups represented in the district AIDS committee structures denies the exercise of their oversight roles of the district HIV response and encourages speculation that administrators have something to hide. Political representatives, as evidence of this view, said that, "People sit in the office and write proposals to the NAC... they are buying new cars. If money comes in we are not told. We do not know who is rich from this." Moreover, the information deficit has been pronounced among community representatives with communities who need to access HIV services suffering as a result.

When interrogating social accountability, information deficits were found to be pronounced and it was determined that citizens lack information on a number of issues that would enable them to participate effectively in HIV governance. Citizens do not always know what channels to use to report abuse or to register dissatisfaction with HIV and AIDS services. This was a generic problem across all five districts. As a result of a lack of knowledge of rights, citizens were perceived to be afraid to complain because officials are seen to protect themselves and each other. In addition, institutional structures, such as the community AIDS task forces (Zambia) and the community AIDS coordinating committees and their rural counterparts, the village AIDS committees (Malawi) that are supposed to accommodate citizen participation in HIV governance were either not functioning well or were entirely moribund. As a result, citizens were not participating in the setting of district HIV planning priorities, the funding of AIDS activities or in the dissemination of information. 
Participation examined the level of citizen engagement in public fora and in civil society organisations under the headings of created space and claimed space respectively. Participation appeared to be fraught with information gaps. In some districts, the private sector was excluded. In Mchinji and Mzuzu, the private sector was not represented in the District AIDS Council. Steps were taken during the course of the implementation term to form private sector HIV committees that could elect functional representation to the DAC. In Mangochi, the civil society organisations noted that they had allowed their networks to lapse and used the opportunity created by the implementation of the project to reinvigorate their committee membership. Committee membership forms the basis of a formal networking coordination committee from which the representation the CSOs have on the district AIDS committee derives.

Administrative channels of complaint and participation were not widely known in all 5 districts. In Mangochi, private sector stakeholders were keen to learn how to participate in HIV governance. When it was suggested that they may be able to gatecrash district HIV meetings, as part of their rights of representation, one of the participants claimed that, "We do not even know where the gate is." This view was widely held in most of the districts where suggestion boxes in district offices and clinics were mistrusted by citizens and seen to be substitutes for direct communication and substantive public participation. The use of suggestion boxes was also problematic due to the lack of feedback and accountability built into the anonymity of the process. Because of the district administrative staff's lack of interaction with citizens, administrative and financial decisions are not explained and complaint mechanisms are not widely known or understood. Insofar as participation of the community was concerned, citizens were on the receiving end of a defective information feedback system. Politicians, as community representatives, were not involved in HIV activities. As a result, they were not geared to provide citizens with relevant and topical information on HIV and AIDS activities in the district. Moreover, complaint mechanisms in the district were not known to the citizens, and even the widely known and demarcated channel of elected representatives was in many instances inoperable. Alternative channels were identified in Mzuzu, where the citizens accessed information through informal networks. People had devised means of obtaining information but it is not possible to rely exclusively on communication obtained on an informal basis to guide formal organisational actions.

Dissemination of information and public meetings organised by administrators and officials were cited as problems in Zambia, particularly in Choma where it was noted that the local mobile phone service provider offers 100 free text messages if one sends 10 text messages. It was suggested that this communication medium could be used to reach stakeholders to notify them of meetings, changes to budgets and possibly even stock outs of antiretroviral therapy (ART) at the clinics.

The principle of equity was included to determine the impediments to equal access to services and participation in planning and budgeting. Of all the pillars of governance, equity consistently performed well in the perceptions of the stakeholders. Men and women viewed access to medication as equitable, planning and budgeting as gender friendly and participation as free and equal. 


\section{Analysis of national governance issues inferred from findings at the local level}

General issues emerging from implementation include a lack of hard evidence to drive decisionmaking and planning. The Know Your Epidemic (KYE) response system was and remains a pipedream due to the lack of hard data in the districts. Moreover, in Zambia, the National AIDS Strategic Framework acknowledges that the principle shortcoming of prevention activity is "the inadequate use of evidence to inform program decisions". If this is the case at the national level, it is, on a balance of probabilities, worse at district level where information is less accessible or available.

From the above fieldwork evidence, planning, coordination, accountability and communication are issues occurring at the national level which filter down to the districts. Planning at national level is participatory and open to organised networks. However, at the district level, planning is widely perceived as exclusive. Planning priority areas are not shared between the stakeholders in the multisectoral response. In some districts, it was claimed that the NAC imposes a plan, directly through prescription or indirectly through the manipulation of the districts' submitted budget. As a result, districts are left without the means to address the local HIV conditions, which are often unique, localised and specific. Even if districts had hard evidence, chances are they would not be empowered to plan effective and implementable local responses.

Coordination is a massive problem that starts at the level of planning. National plans are not universally known which affects coordination at the district level. Some activities of the national AIDS plans are over-serviced at the district level, such as prevention and awareness, while others, such as monitoring, evaluation and treatment, are underserviced. Legality of enforcement is not known and consequently MoUs are not enforced, hampering active coordination of the HIV multisectoral response at district level. In part, coordination is hamstrung by implementing partners who do not declare external funding to the District AIDS Coordinators. This hampers efforts to direct resources into priority areas. Coordination is further impeded by centralised funding sources. The NACs in Malawi and Zambia have been said not to release funding on time due to lengthy administrative procedures, impeding activity implementation.

Accountability is affected by widespread information asymmetries. Administratively, in all districts, participants in all stakeholder categories remarked that the heads of department do not share information. The national AIDS plan is not distributed and its activity areas are not publicised within departments or among district stakeholders in the HIV multi-sector response. Task specific top-down delegation without broader information sharing is identified as a common concern among all stakeholders, even government employees. Minutes from HIV meetings of the council are not circulated and heads and senior staff do not brief junior staff on information obtained from 'high level' line ministry and district council meetings. 
While citizens participate at the national policy drafting level through AIDS service organisations and national networks, participation at the district level is neither substantive nor consultative. This impedes the formation of accountability networks with citizens at the centre of the response. Instead, citizens are beneficiaries and consumers of services, who cannot, through their lack of civic education, exert their influence effectively enough to enforce the social contract that is democratic accountability.

Lack of communication and consequently insufficient transparency underpin all the above issues. A lack of communication leads to opacity in decision-making. The information might be available but if it is not communicated and people do not see how decisions are arrived at, speculations of corruption may flourish, when this may not be the case at all. Communication affects the capacities for planning, participation and accountability. If objectives are not clearly communicated, coordinated implementation of HIV related social services, for home-based care, orphan-related services, support groups and service access, is bound to suffer, particularly at the local level, where coordination is crucial to meeting the needs of citizens. This is primarily an issue originating at national level, and replicating at the local level. If actors in the local HIV response are not communicative of funding, funding sources, activities and internal process, they are not transparent. The information they release will be of little value as will not be verifiable and accountability will be eroded. It is up to the national government to ensure that the district leadership communicates the plans, objectives and budgets for HIV activities by improving national oversight and evaluation and promoting local public engagements. 


\section{Recommendations}

The issue to be addressed underlying all the issues is that of coordination. Coordination can be improved through the following steps:

- National AIDS plans must be as widely disseminated as possible. Where possible, district meetings including the representatives from all designated stakeholder groups must be held and the activities and budgets of the national and district response declared.

- Any budget shortfalls and deviations must be transmitted through stakeholder representatives to the $\mathrm{CBO} / \mathrm{NGO}$ networks.

- The district should have a coordination strategy in place and make use of the legal backing of the NAC to enforce agreements reached with implementing partners under Memoranda of Understanding. Bylaws can be utilised to stipulate penalties.

- Periodic structured ad hoc verbal reviews of activities at the district level conducted by the AIDS Coordinators among major stakeholders can assist the district build an anecdotal picture of the district's implementation of HIV activities to guide coordination of implementation. This could be a strategy employed at the district level where budgets are often too limited to meet the demands of routine service delivery.

- An activity coordination framework should be drafted and distributed among HIV multisector stakeholders. Duplication and over-servicing should be minimised through consensus and information sharing at the community network level at regular intervals.

- Accountability mechanisms should be put in place to compel senior staff to share information with subordinates and junior staff. Briefing meetings should be regularly held and full documentation, such as meeting minutes and planning documents, supplied for general consumption.

- Communication channels should be examined and cost-effective responses used for the purposes of coordinating an effective response. In the instance of text messaging, other channels can also be identified, such as Twitter and Facebook. These are generally low cost and high volume communication methods where persons of limited means own or have access to mobile devices. Service agreements with telecommunications service providers for discounted rates for AIDS response personnel can be negotiated through the NAC, driven by demand from the community level. 


\section{Conclusion}

While there are many challenges in implementing effective HIV responses at the district level, it must be said that much has been achieved. International support has made for effective treatment but the social capital to sustain effective community-owned responses has often been neglected in national planning and in international development partner interventions.

The identification of the above problem areas illustrates how much more effective the response can be made even if monetary resources are short. While access to medical services is specialised, such services can be made more effective by addressing the issues of governance implied in the coordination of the HIV response and the delivery of non-biomedical services, such as home-based care, orphan support, prevention and support and income generating activities for widows and orphans. Addressing information gaps and accountability mechanisms are crucial in the building of effective coordination networks at the district and community level.

If we are to reach the targets set in the Millennium Development Goals, improving the stewardship of resources is not only imperative, it demands additional support. This support cannot be sourced from lending institutions or from development partners and might not necessarily be financial. Community resources should be considered as a part of the support brought to bear on the HIV response. Community-led resource mobilisation is one such way to improve the effectiveness of service delivery in the HIV sector. Promoting community ownership of the HIV response through improved democratic governance that conforms to the principles of governance is perhaps the strongest contribution districts can make to fight the HIV epidemic over the long term. Building consensus around what needs to be done can hone the HIV response as well as provide a catalyst for improving communication and information between governance and between governors and the governed.

Before community engagement is broached, issues within district AIDS governance relationships must be clarified. Clear mandates, defined lines of authority, specific roles for locally elected representatives and public participation requirements must be firmly set out to improve local involvement in HIV sector governance. Providing local government with mandates to assume control of HIV administration is critical to bringing governance to the administrative level closest to the citizen.

\section{References}

Bratton, M. and Sibanyoni, M. 2006. Delivery or Responsiveness? A Popular Local Governance Scorecard of Local Government Performance in South Africa. Paper 62. Pretoria: Idasa.

National AIDS Commission of Malawi. 2009. Extended National Action Framework (NAF) 2010-2012. Malawi: Office of the President.

National AIDS Council of Zambia. 2010. National AIDS Strategic Framework 2011-2015. Zambia: Ministry of Health.

UNAIDS. 2010. Getting to Zero: 2011-2015 Strategy. [Accessed; 25 September 2013] www.unaids.org/en/media/unaids/contentassets/documents/unaidspublication/2010/jc2034_unaids_strategy_en.pdf

Whiteside, A. and Sunter, C. (2001). AIDS: The Challenge for South Africa. Cape Town: Tafelberg. 